\title{
A METASTASING CHORDOMA
}

\author{
A Further Note \\ John Chalmers and B. E. Heard, Edinburgh, Scotland \\ From the Department of Orthopaedic Surgery and Pathology, Edinburgh University'
}

In 1960 Chalmers and Coulson reported a case of a sacral chordoma which was unusual in that it showed a tendency to metastasise to muscle and subcutaneous fat. The subsequent progress of this patient continued to be remarkable. Since the earlier report she produced over the years seven more metastases in muscle, making ten in all, and a second metastasis in subcutaneous fat. Each of these was treated by local excision without local recurrence.

Four days after the excision of five muscle metastases in August 1968 the patient died suddenly and unexpectedly at the age of sixty-six, nearly fifteen years after the original excision of the primary tumour.

TABLE I

Main Events in the Clinical History

\begin{tabular}{|c|c|}
\hline Date & Clinical feature \\
\hline & $\ldots$ \\
\hline November 1953 & Excision of primary tumour of sacrum \\
\hline January 1959 & First metastasis, in biceps muscle right arm \\
\hline December 1959 & $\begin{array}{l}\text { Second metastasis, in long head of triceps right arm. } \\
\text { Third metastasis, in subcutaneous fat left arm }\end{array}$ \\
\hline February 1960 & Fourth metastasis, in brachialis muscle right arm; excision of local recurrence in sacral area \\
\hline December 1963 & Fifth metastasis, in subcutaneous tissue right pectoral region \\
\hline March 1966 & Sixth metastasis, in right thenar muscles \\
\hline February 1967 & Seventh metastasis, in left quadriceps muscle \\
\hline July 1968 & $\begin{array}{l}\text { Eighth, ninth, tenth, eleventh and twelfth metastases, in right extensor carpi radialis } \\
\text { brevis, right deltoid, right gluteus maximus (two lesions) and right quadriceps. Four } \\
\text { days later, sudden death ascribed to metastasis in ventrical septum }\end{array}$ \\
\hline
\end{tabular}

At necropsy a metastasis was found in the cardiac muscle which presumably had led to her death. Until then she had remained in apparently good health and led a normal active life.

The main events in her unusual medical history are listed in Table I.

Necropsy-Necropsy was performed two days after death. The heart, $425 \mathrm{~g}$, was the site of a secondary deposit of chordoma. It lay in the upper anterior part of the interventricular septum (Fig. 1), was firm in consistency and the cut surface was pale with one small haemorrhage. There were a number of soft jelly-like areas which were partly translucent. The edge bordering on cardiac muscle was fairly sharp but the tumour was not encapsulated.

Histologically, the myocardial deposit of chordoma was more cellular than the primary growth. The cells were moderately pleomorphic with abundant clear, vacuolated or finely granular eosinophilic cytoplasm, and single round, oval, fusiform or irregular nuclei with coarsely stippled chromatin. Mitoses were rare. Intercellular mucin was abundant in some areas but scanty in others where the cellularity was great (Fig. 2). Some cells showed numerous cytoplasmic vacuoles and were physaliphorous in appearance. Very large cells with enormous 


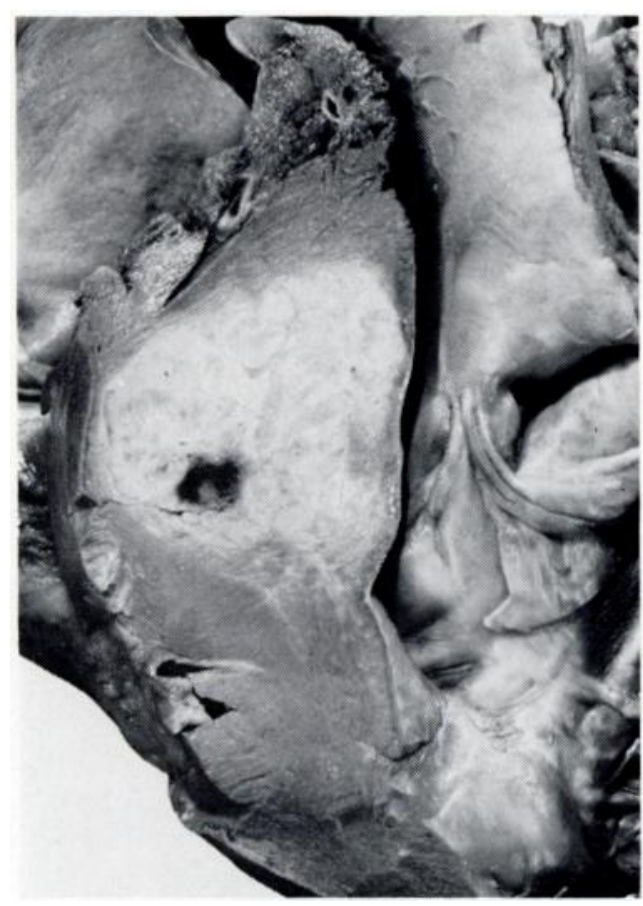

Fig. 1

Myocardial deposit of chordoma. The large pale area above and to the left of the centre of the photograph is tumourinvolving the interventricular septum. ( $\times 2$.

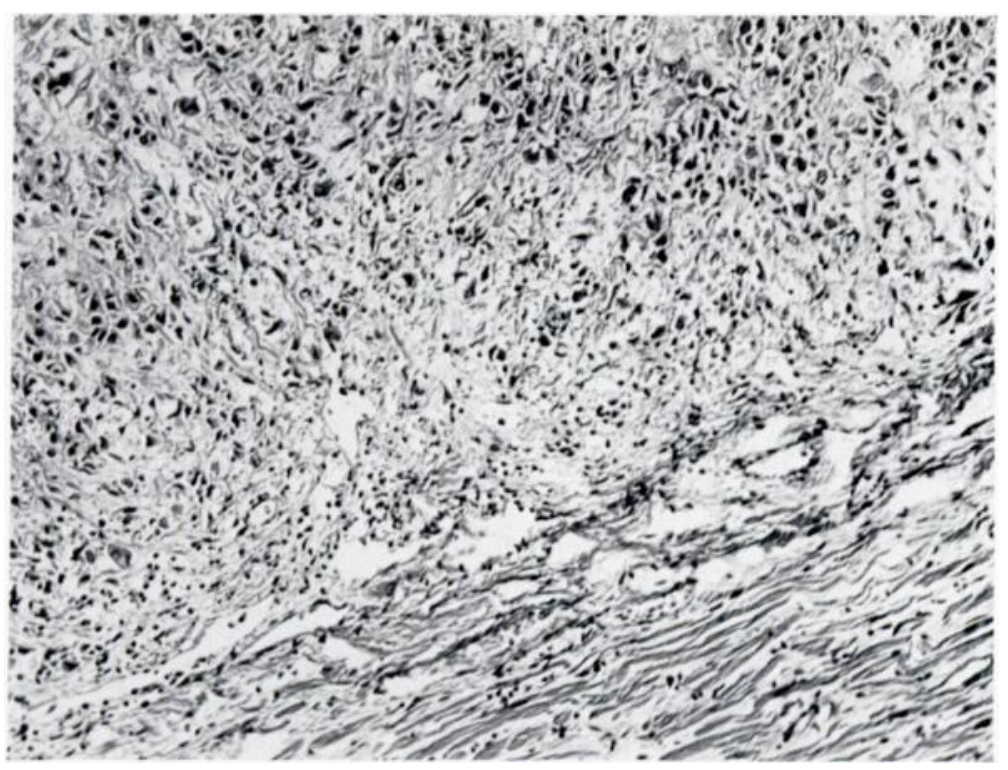

FIG. 2

Myocardial deposit of chordoma. Histological appearance of a highly cellular area of the tumour. The cells here are pleomorphic and there is only a small amount of intercellular mucin. The transition from tumour to myocardium (lower end of photograph) is sharp. (Haematoxylin and eosin, $\times 85$.) 
single nuclei were present in a few sites. Parts of the growth were composed of masses of mucin with very few tumour cells lying singly in it.

Other positive findings at necropsy were gall-stones, congestion and slight oedema of the lungs, a congested haemorrhagic spleen, an angio-lipoma 2 centimetres diameter of the left kidney, and changes of Parkinsonism in the brain. There was no residual tumour in the sacral region, and no deposits of chordoma were found elsewhere than in the myocardium.

\section{DISCUSSION}

Dr H. A. Sissons has kindly reviewed the histological features and comments that the myocardial lesion has features suggestive of chondrosarcoma, in contrast to the other metastases which were typical of chordoma. Histological similarities between chordoma and chondrosarcoma are well recognised (Jaffe 1958, Lichtenstein 1965), but the diagnosis can usually be resolved if adequate biopsy material is available, as in this case. Crawford (1958) indicated some histochemical staining reactions which are useful in differentiating between these two tumours.

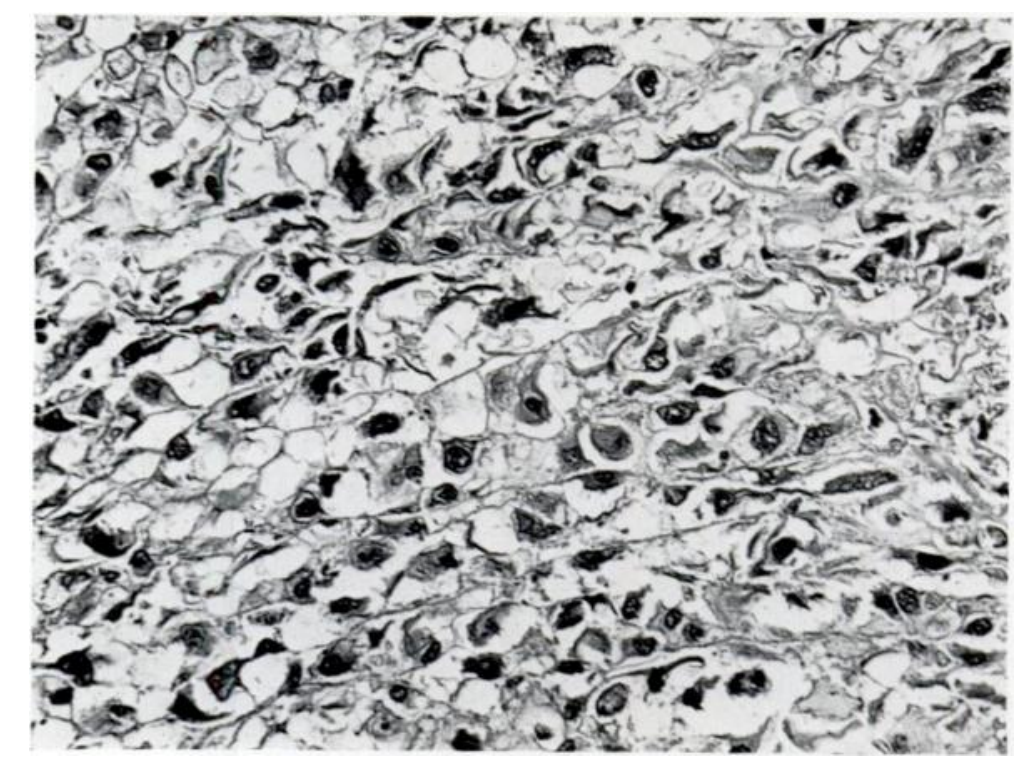

Fig. 3

A higher power view of another field of the myocardial metastasis showing physaliphorous cells similar to those of the primary tumour. (Haematoxylin and eosin, 260.)

Since the original report of this case three similar cases have been recorded. Whitaker and Cast (1969) described a man aged fifty-five at the time of presentation who survived for twenty years after resection of a sacro-coccygeal tumour. During this period he developed several metastases in the gluteal and calf muscles, all of which were removed. He died ultimately from local recurrence with paraplegia.

Wang and James (1968) reported the case of a man aged fifty-nine also with a sacrococcygeal primary tumour who developed widespread metastases in muscle and subcutaneous tissues. Radiotherapy was used to treat the primary and metastatic lesions, with short-term regression of the tumours. At his death eleven years later metastases were found in lung, pleura, pericardium, myocardium, retroperitoneum and liver in addition to the muscle and subcutaneous deposits. 
Scevola, Matteis, Tempia and Fossati (1966) reported the case of a man aged sixty-four who had had a coccygeal chordoma excised fifteen years before. A muscle metastasis first appeared in one arm five years after the initial presentation, and during the next six months two further muscle metastases developed in an arm and in latissimus dorsi. These were excised and the patient was alive at the time of their report.

Higinbotham, Phillips, Farr and Hustu (1967) in a study of forty-six patients with chordoma found metastases in $\mathbf{4 3}$ per cent, a much higher figure than in any other recorded series. The most frequently affected tissues were lung, bone and liver. Metastases to skeletal muscle were not described but the authors did refer to myocardial involvement without indicating its frequency.

Fox, Batsakis and Owano (1968) reviewed forty-seven reported cases of metastasising chordoma. The lung, liver, bone and lymph nodes were confirmed as the most common affected sites. No muscle metastases were described in their review but one case with myocardial metastasis was included (Willis 1930).

These recent reports indicate that although chordomas may metastasise widely, involvement of skeletal muscle and myocardium is distinctly uncommon. Surgical excision of accessible metastases appears to be a worthwhile palliative procedure.

We are grateful to $\mathrm{Mr}$ W. A. Souter, who looked after the patient during her terminal illness, for making his records available to us.

\section{REFERENCES}

Chalmers, J., and Coulson, W. F. (1960): A Metastasising Chordoma. Journal of Bone and Joint Surgery, 42-B, 556.

Crawford, T. (1958): The Staining Reactions of Chordoma. Journal of Clinical Pathology, 11, 110.

Fox, J. E., Batsakis, J. G., and Owano, L. R. (1968): Unusual Manifestations of Chordoma. Journal of Bone and Joint Surgery, 50-A, 1618.

Higinbotham, N. L., Phillips, R. F., Farr, H. W., and Hustu, H. O. (1967): Chordoma. Thirty-five Year Study at Memorial Hospital. Cancer, 20, 1841.

JAFFE, H. L. (1958): Tumors and Tumorous Conditions of the Bones and Joints, p. 460. London: Henry Kimpton. Lichtenstein, L. (1965): Bone Tumors. Third edition, p. 320. St Louis: C. V. Mosby Co.

Scevola, G., De Matteis, R., Tempia, G., and Fossati, G. (1966): Su di un caso di cordoma metastatizzato. Minerva Chirurgica, 21, 789.

WANG, C. C., and JAmes, A. E., Jr. (1968): Chordoma: Brief Review of the Literature and Report of a Case with Widespread Metastases. Cancer, 22, 162.

Whitaker, R. H., and Cast, I. P. (1969): Prolonged Survival in a Case of Sacrococcygeal Chordoma with Metastases. British Journal of Surgery, 56, 392.

Willis, R. A. (1930): Sacral Chordoma with Widespread Metastases. Journal of Pathology and Bacteriology, 33, 1035. 